\title{
AGROPEDOGENIC TRANSFORMATION OF PHYSICAL PROPERTIES OF SOILS OF MEDIUM-DRY STEPPE PEDO-ECOTONE IN THE NORTHWEST OF THE BLACK SEA REGION
}

\author{
Hryhorii MOROZ, Peasant Farm Enterprise "Balkany", Sarata, 68202, Odessa region, Ukraine, morozgrisha@ gmail.com
}

The anthropogenic transformation of soil physical properties of the transition stripe from the dry to the middle steppe in the Northwest of the Black Sea region is considered and analyzed on the basis of comparison of indicators characterizing the properties of the cultivable and subcultivable horizons. The signs of negative influence of agricultural use on the most important indices of physical properties of soils are investigated. Significant degradation of the physical properties of the arable horizons (in comparison with tillable and subcultivable horizons), as well as deterioration of the water resistance of the structure of the tillable horizons (compared to the arable) was revealed. The geographic regularities of agrogenic evolution of sodic and residual-sodic calcic chernozems and gypsic kastanozems are established.

Keywords: agropedogenic transformation of soils, calcic chernozems, gypsic kastanozems, pedo-ecotone, physical properties, steppe.

\section{INTRODUCTION}

Nowadays, there is no clear concept of agrogenic evolution of soils, including in the transition stripe from the dry to the middle steppe. The reason for this is a long-term one-sided utilitarian consideration of the problem of agrogenic evolution of soils, separately from the general direction of the evolution of steppe landscapes as a whole. This is also emphasized by the fact that nowadays many scientists do not consider agricultural soils as a special category of objects, which are fundamentally differ from the natural analogues (Degradation and protection of soils, 2002; Karavaeva, 2005).

The basis of anthropogenic soil change is the violation of the quasi-equilibrium between the factors of soil formation and soil forming processes. Breaking and changing the main factors of soil formation, the human changes the course and the direction of soil forming processes, resulting in a profound transformation of soils' properties (Volungevičius, Skorupskas, 2011; Dazzi, Lo Papa, 2015). Therefore, the current state of pedogenesis in the transition stripe from the medium to the dry steppe (medium-dry steppe pedo-ecotone) is due to the dualistic cyclicity of the functioning of cultivated lands - natural and agrogenic. Natural cycles are associated with natural daily, annual and perennial rhythms. Its main components are the humus and the soil structure formation, and migration of carbonates, which are determined by the bioclimatic conditions of the territory. The agrogenic cycle is also characterized by a clear rhythm during the agricultural year, but it is shifted according to the most cardinal anthropogenic impacts on the soil. Components of this cycle are densification, destructuring, crust formation, excessive compactness, etc (Jovanov, 2012; Howard, 2017).

It is proved that the agrogenic processes are not random and chaotic, but they are correlated and depend on the initial soil state. Thus, they amplify or modify natural soil forming processes and give to the soils new functions (functiontransformational and regime-transformational), or they affect only the individual elements of the soil profile and do not violate the general course and orientation of the soil forming process (morpho-transformational) (Jigau, 2008; Zalibekov, Biarslanov, 2015). Permanent anthropogenic impact on soils causes the development of new, non-typical for virgin soils, and a violation of the natural soil-forming processes. All this leads to a gradual reorganization of soil formation into the natural-anthropogenic type, while the general direction of the chernozem type of pedogenesis remains (Jigau, 2017).

Therefore, the modern soils evolution in the transitional stripe from the middle to the dry steppe is determined by the effective integration of both interrelated and mutually conditioned forms of evolution - natural and agrogenic, which create the unified natural-anthropogenic soil ecosystem. Within this ecosystem, the agrogenic profile is formed, which is a unified genetic entity the functioning of which is determined by the natural processes of decomposition and synthesis of organic matter, as well as agrogenic processes of transformation of the initial and the brought mineral matter (Degradation and protection of soils, 2002; Nosko, 2013).

Copyright (C) 2017 The Authors. Published by Aleksandras Stulginskis University. This is an open-access article distributed under the terms of the Creative Commons Attribution License (CC-BY 4.0), which permits unrestricted use, distribution, and reproduction in any medium, provided the original author and source are credited. 


\section{MATERIALS AND METHODS}

The object of the study are the soils of the medium-dry steppe pedo-ecotone in the Northwest of the Black Sea region and their anthropogenic transformation. One of the main methods for studying the depth of the transformation of soils under the anthropogenic influence is the comparison of the differences between the properties of the cultivable and the subcultivable horizons. Since the negative aspects of the agropedogenesis are reflected differently in the cultivable and in the subcultivable horizons, in our opinion, the transformation of the physical properties of the studied soils should be considered comparing the properties of the tillable, arable and subcultivable horizons.

Structural composition of soils was determined using a sieving method, according to Savvinov (Theory and Methods of Soils Physics, 2007). The structural coefficient (SC) was calculated as the ratio of the content of macro aggregates in the size of $0.25-10 \mathrm{~mm}$ (A) to the total amount of $>10 \mathrm{~mm}$ macro-aggregates and $<0.25 \mathrm{~mm}$ aggregates (B) (formula 1).

$$
\mathrm{SC}=\mathrm{A} / \mathrm{B},
$$

Water resistance criterion (WRC) was calculated as the ratio of the content of structural fractions of 1-0.25 mm, obtained during the wet sieving (C) to the content of structural fractions of 1-0.25 mm, obtained during the dry sieving (D), multiplied by $100 \%$ (formula 2 ).

$$
\mathrm{WRC}=(\mathrm{C} / \mathrm{D}) * 100 \%
$$

Indicator of water resistance (IWR) was calculated by formula 3 as the ratio of the content of waterproof aggregates in the size of $>0.25 \mathrm{~mm}$ (E) to the content of aggregates in the size of $>0.25 \mathrm{~mm}$, obtained by dry sieving (F), multiplied by $100 \%$.

$$
\operatorname{IWR}=(\mathrm{E} / \mathrm{F}) * 100 \%
$$

\section{RESULTS AND DISCUSSION}

Agropedogenic soil transformation is a consequence of the transformation of soil regimes and soil forming processes, which in turn are a function of the transformation of the environment. Therefore, due to the nature of the main processes, the agropedogenic transformation of soils can be divided into three groups: physical, chemical and biological (Degradation and protection of soils, 2002).

Physical transformation of soils is a change in the complex of physical properties or in the physical state of soils, which is characterized by certain quantitative parameters. The basis of all physical and other changes occurring in the agropedogenesis is the transformation of the natural soil profile into agrogenic soil profile. The humused part of the natural soil profile within the research area is clearly divided into two horizons - cultivable $(12-30 \mathrm{~cm})$ and subcultivable $(30-55 \mathrm{~cm})$. The upper horizon is often divided into two layers - tillable $(0-12 \mathrm{~cm})$ and arable $(12-30 \mathrm{~cm})$. Often the arable layer coincides with the humus-accumulative horizon (A), however, sometimes the latter is characterized by greater depth (up to $46 \mathrm{~cm}$ ). In such case, the $A$ arable and $A B$ subcultivable horizons are divided by the subplough sole, which is characterized by a high density of soil.

According to the generalized data of many scientists, in arable soils, the depth of the humus accumulative horizon (A) is $6 \mathrm{~cm}$, on average, higher than in virgin soils (Degradation and protection of soils, 2002; Nosko, 2006), which is confirmed by practically the same depth of the horizon A in the studied soils (compared with calcic chernozems). This is due to the greater depth of penetration of the root system of cultivated plants, as well as the washing out of soluble humus substances under the influence of atmospheric precipitation on arable lands. The proof of the latter may be the descension of the effervescence from $10 \% \mathrm{HCI}$ line from the lower limit of the AB horizon in the soils of the plakors and the lower

\begin{tabular}{|c|c|c|c|c|c|c|}
\hline \multirow{3}{*}{\multicolumn{2}{|c|}{ Soil genetic horizons indexes }} & \multirow[b]{2}{*}{$\begin{array}{c}\text { Calcic Chernozems } \\
(\mathrm{n}=9)\end{array}$} & \multicolumn{3}{|c|}{ Calcic Chernozems Sodic and Recidual-Sodic } & \multirow[b]{2}{*}{$\begin{array}{c}\text { Gypsic } \\
\text { Kastanozems Sodic } \\
(\mathrm{n}=1)\end{array}$} \\
\hline & & & $\begin{array}{l}\text { Plakors } \\
(n=17)\end{array}$ & $\begin{array}{l}\text { Upper parts of } \\
\text { slopes }(n=16)\end{array}$ & $\begin{array}{c}\text { Lower parts } \\
\text { of slopes } \\
(n=17)\end{array}$ & \\
\hline & & Limit $\mathrm{ql}$ & er limit of $t$ & $\begin{array}{l}\mathrm{netic} \text { horizon } \pm \mathrm{st} \\
\mathrm{r} \text { limit of the gen }\end{array}$ & $\begin{array}{l}\text { dart deviation } \\
\text { c horizon }(\mathrm{mi}\end{array}$ & $\frac{\mathrm{m}}{\operatorname{nax}), \mathrm{cm}}$ \\
\hline \multirow{2}{*}{ A cultivable } & A tillable & $\frac{11 \pm 1.1}{9-12}$ & $\frac{10 \pm 1.1}{9-12}$ & $\frac{10 \pm 1.1}{9-12}$ & $\frac{11 \pm 1.0}{9-12}$ & $\frac{7}{7}$ \\
\hline & A arable & $\frac{29 \pm 1.4}{27-30}$ & $\frac{26 \pm 3.1}{18-30}$ & $\frac{24 \pm 1.6}{20-27}$ & $\frac{24 \pm 2.6}{18-30}$ & $\frac{30}{30}$ \\
\hline \multirow{2}{*}{$\begin{array}{l}\text { Subcultivable } \\
\text { horizons }\end{array}$} & A & $\frac{35 \pm 5.4}{27-45}$ & $\frac{35 \pm 1.2}{27-46}$ & $\frac{31 \pm 0.7}{23-35}$ & $\frac{35 \pm 1.5}{21-45}$ & $\frac{30}{30}$ \\
\hline & $\mathrm{AB}$ & $\frac{55 \pm 2.1}{52-60}$ & $\frac{52 \pm 1.4}{40-60}$ & $\frac{43 \pm 1.4}{32-54}$ & $\frac{49 \pm 1.6}{37-56}$ & $\frac{43}{43}$ \\
\hline \multicolumn{2}{|c|}{$\begin{array}{c}\text { Depth of the strong } \\
\text { effervescence from } 10 \% \mathrm{HCI}\end{array}$} & $\frac{55 \pm 8.8}{45-78}$ & $\frac{56 \pm 1.8}{46-75}$ & $\frac{42 \pm 3.6}{0-66}$ & $\frac{57 \pm 4.4}{30-85}$ & $\frac{43}{43}$ \\
\hline
\end{tabular}
parts of the slopes (Table 1).

Table 1. Morphometric characteristic of soils (average values) 
The most important property of the agrogenic part of the soil profile is the stability in the time of the favorable properties created by the human and the conditions under which they are determined (Karavaeva, 2005). Arable horizons of the investigated soils belong to the subclass of the light alkaline of typical arable horizons class (according to the classification of Karavaeva). These arable horizons are characterized by a certain set of properties that provide a good development of crops and the subsequent yield. These properties include: homogeneity of the soil mass, close to neutral or low-alkaline $\mathrm{pH}$, sufficient content of the humus and the plant nutrition elements, favorable physical and water-physical properties of the cultivable horizon.

However, despite the positive, there are a number of negative consequences of the cultivation of the humus accumulative horizon on the researched territory. Thus, under the influence of agriculture, the humus of arable horizons becomes more mobile, as its reproduction occurs, apparently, by increasing the content of labile substances peptized by water. This leads to a considerable deterioration of the physical properties of the arable horizons: the content of cloddy (20-30\%) and dust (5-15\%) aggregates increases, the surface is broken up with the formation of blocks (Table 2), which is also noted in other regions of the spread of chernozem soils (Laktionov, 1970; Degradation and protection of soils, 2002; Nosko, 2006; Paluszek, 2014).

Table 2. Aggregate composition of soils (average values)

\begin{tabular}{|c|c|c|c|c|c|c|c|c|c|c|c|c|c|}
\hline \multirow{3}{*}{ 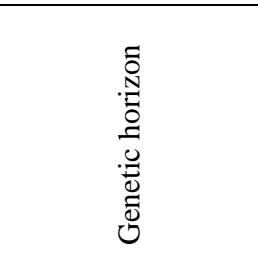 } & \multirow{3}{*}{ 营 } & \multicolumn{10}{|c|}{ Dimensions of aggregates, $\mathrm{mm}$} & \multirow{3}{*}{$U$} & \multirow{3}{*}{ 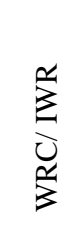 } \\
\hline & & \multicolumn{10}{|c|}{$\frac{\text { dry sieving, \% }}{\text { wet sieving, } \%}$} & & \\
\hline & & $\stackrel{\circ}{\pi}$ & $\hat{\jmath}$ & $\stackrel{n}{r}$ & $\hat{n}$ & $\tilde{n}$ & $\bar{\lambda}$ & $\stackrel{n}{1}$ & $\begin{array}{l}\text { ñ } \\
0 \\
\stackrel{1}{n} \\
o\end{array}$ & $\begin{array}{l}\tilde{n} \\
\stackrel{0}{v}\end{array}$ & 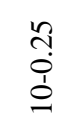 & & \\
\hline 1 & 2 & 3 & 4 & 5 & 6 & 7 & 8 & 9 & 10 & 11 & 12 & 13 & 14 \\
\hline \multicolumn{14}{|c|}{ Calcic Chernozems $(n=6)$} \\
\hline A tillable & $0-11$ & $\frac{20.5}{-}$ & $\frac{8.8}{-}$ & $\frac{7.1}{-}$ & $\frac{7.3}{0.4}$ & $\frac{5.8}{4.9}$ & $\frac{22.1}{9.6}$ & $\frac{5.5}{12.8}$ & $\frac{13.0}{24.3}$ & $\frac{9.9}{48.0}$ & $\frac{69.6}{52.0}$ & 2.29 & $\frac{200.5}{74.7}$ \\
\hline A arable & $11-29$ & $\frac{31.5}{-}$ & $\frac{11.1}{-}$ & $\frac{8.7}{-}$ & $\frac{9.5}{0.5}$ & $\frac{7.3}{4.1}$ & $\frac{18.9}{12.3}$ & $\frac{3.8}{12.3}$ & $\frac{5.2}{23.3}$ & $\frac{4.0}{47.5}$ & $\frac{64.5}{52.5}$ & 1.82 & $\frac{395.6}{81.4}$ \\
\hline AB subcultivable & $35-55$ & 34.2 & 12.4 & 9.5 & 6.3 & 9.7 & 18.7 & 2.5 & 4.3 & 2.4 & 63.4 & 1.73 & - \\
\hline \multicolumn{14}{|c|}{ Calcic Chernozems Sodic and Residual-sodic (plakors) $(n=7)$} \\
\hline A tillable & $0-10$ & $\frac{22.1}{-}$ & $\frac{7.4}{-}$ & $\frac{8.9}{-}$ & $\frac{9.3}{0.3}$ & $\frac{8.5}{1.4}$ & $\frac{16.9}{6.6}$ & $\frac{6.7}{7.8}$ & $\frac{7.7}{18.2}$ & $\frac{12.6}{65.7}$ & $\frac{65.3}{34.3}$ & 1.88 & $\frac{180.6}{52.5}$ \\
\hline A arable & $10-26$ & $\frac{29.2}{-}$ & $\frac{8.1}{-}$ & $\frac{9.2}{-}$ & $\frac{10.9}{0.5}$ & $\frac{9.3}{3.1}$ & $\frac{15.0}{9.5}$ & $\frac{5.5}{7.4}$ & $\frac{6.3}{16.3}$ & $\frac{6.7}{62.6}$ & $\frac{64.2}{37.5}$ & 1.79 & $\frac{200.9}{58.4}$ \\
\hline AB subcultivable & $35-52$ & 34.0 & 9.5 & 11.9 & 11.9 & 11.1 & 10.4 & 3.1 & 4.6 & 3.5 & 62.5 & 1.67 & - \\
\hline \multicolumn{14}{|c|}{ Calcic Chernozems Sodic and Residual-sodic (upper parts of slopes) $(n=5)$} \\
\hline A tillable & $0-10$ & $\frac{22.7}{-}$ & $\frac{7.7}{-}$ & $\frac{7.2}{-}$ & $\frac{8.4}{-}$ & $\frac{9.7}{0.8}$ & $\frac{15.6}{2.7}$ & $\frac{5.6}{5.8}$ & $\frac{9.2}{20.1}$ & $\frac{13.9}{70.6}$ & $\frac{63.4}{29.4}$ & 1.73 & $\frac{175.0}{46.4}$ \\
\hline A arable & $10-24$ & $\frac{30.5}{-}$ & $\frac{8.8}{-}$ & $\frac{8.4}{-}$ & $\frac{11.4}{-}$ & $\frac{10.2}{1.2}$ & $\frac{12.7}{3.0}$ & $\frac{4.3}{7.6}$ & $\frac{6.0}{23.2}$ & $\frac{7.8}{64.8}$ & $\frac{61.7}{35.2}$ & 1.61 & $\frac{299.0}{57.1}$ \\
\hline AB subcultivable & $31-43$ & 32.0 & 10.2 & 10.3 & 12.7 & 10.3 & 10.9 & 3.5 & 3.5 & 6.5 & 61.4 & 1.59 & - \\
\hline \multicolumn{14}{|c|}{ Calcic Chernozems Sodic and Residual-sodic (lower parts of slopes) $(n=7)$} \\
\hline A tillable & $0-11$ & $\frac{23.8}{-}$ & $\frac{8.3}{-}$ & $\frac{7.6}{-}$ & $\frac{9.9}{-}$ & $\frac{9.8}{1.7}$ & $\frac{15.2}{5.0}$ & $\frac{6.9}{9.6}$ & $\frac{8.6}{17.5}$ & $\frac{10.1}{65.9}$ & $\frac{66.2}{34.1}$ & 1.95 & $\frac{174.8}{51.5}$ \\
\hline A arable & $11-24$ & $\frac{31.7}{-}$ & $\frac{7.9}{-}$ & $\frac{9.2}{-}$ & $\frac{10.7}{-}$ & $\frac{9,8}{2.3}$ & $\frac{11.3}{6.5}$ & $\frac{4.9}{8.7}$ & $\frac{6.4}{20.9}$ & $\frac{8,2}{61.2}$ & $\frac{60.2}{38.8}$ & 1.51 & $\frac{262.0}{64.5}$ \\
\hline AB subcultivable & $35-49$ & 27.7 & 10.3 & 10.2 & 12.9 & 12.0 & 12.1 & 4.4 & 5.3 & 5.3 & 67.1 & 2.04 & - \\
\hline \multicolumn{14}{|c|}{ Gypsic Kastanozems Sodic $(\mathrm{n}=1)$} \\
\hline A tillable & $0-7$ & $\frac{10.9}{-}$ & $\frac{7.3}{-}$ & $\frac{7.5}{-}$ & $\frac{10.1}{0.1}$ & $\frac{7.5}{1.6}$ & $\frac{37.2}{6.9}$ & $\frac{6.2}{5.7}$ & $\frac{8.3}{15.0}$ & $\frac{5.0}{70.7}$ & $\frac{84.1}{29.3}$ & 5.29 & $\frac{142.8}{34.8}$ \\
\hline A arable & $7-30$ & $\frac{37.6}{-}$ & $\frac{8.5}{-}$ & $\frac{7.5}{-}$ & $\frac{9.3}{0.3}$ & $\frac{7.1}{3.2}$ & $\frac{15.2}{9.7}$ & $\frac{5.6}{6.3}$ & $\frac{5.1}{12.1}$ & $\frac{4.1}{68.4}$ & $\frac{58.3}{31.6}$ & 1.40 & $\frac{172.0}{54.2}$ \\
\hline AB subcultivable & $30-43$ & 26.1 & 10.0 & 9.1 & 11.6 & 9.3 & 18.1 & 4.6 & 5.4 & 5.8 & 68.1 & 2.13 & - \\
\hline
\end{tabular}

Considering the physical transformation of the soils of the researched area, it is worth focusing on the change in their aggregate composition state. Thus, under the influence of agriculture, their arable horizons are characterized by a significant increase of cloddy type aggregates content (by $50 \%$ in calcic chernozems sodic and residual sodic and by $245 \%$ in gypsic kastanozems sodic) and a decrease in the content of agronomically valuable aggregates (up to $7 \%$ and $31 \%$ respectively), in comparison to the tillable horizons, which is a typical manifestation of excessive compactness.

The increased intensity of compactness in gypsic kastanozems is due to their lower humus content, as well as the reduced resistance to anthropogenic influences (Degradation and protection of soils, 2002; Nosko, 2006). At the same time, the tillable horizons of the studied soils are characterized by a high content of dust (the content of aggregates $<0.25$ $\mathrm{mm}$ is $18-60 \%$ higher than in the arable horizons), which is a consequence of their frequent tillage (Table 3). Strengthening of the processes of compactness and spraying of soil mass in more moisturized soils of lower slopes' parts can be explained both by the washing out of sodium humates down the slope and by the increased content of water-soluble 
humus. In turn, the difference in the aggregate composition between the arable and the subcultivable horizons is considerably more substantial than between tillable and arable ones. Thus, the content of cloddy aggregates in the subcultivable horizons increases by only $5-16 \%$, while in the calcic chernozems residual-sodic of lower parts of the slopes and in gypsic kastanozems - in general, decreases by 13-31\%, in comparison with arable horizons. There is the similar pattern is in the change of the content of agronomically valuable aggregates. However, in the subcultivable horizons of all investigated soils, a significant decrease in the content of dust aggregates (by 17-48\%) is observed. Exceptions are gypsic kastanozems - the dusting of their subcultivable horizons increases by $41 \%$ (Table 3 ).

The development of the negative processes also contributes to the changes in the aggregate composition of the soils of the researched area. Thus, arable horizons are characterized by a decrease in the structural coefficient (by $20 \%$ in calcic chernozems and by $74 \%$ in gypsic kastanozems) compared to the tillable horizons. In turn, the tillable horizons are characterized by a significant deterioration of water stability of structural aggregates. The water resistance criterion is reduced by $20-97 \%$ compared to the arable horizons, and the indicator of water resistance - by $9-56 \%$. In the subcultivable soil horizons of the researched area, there is a slight decrease in the structural coefficient - by 1-7\%, and in the soils of the lower parts of the slopes and gypsic kastanozems - a significant increase of 35-52\% (Table 3).

Table 3. Transformation of physical properties in the agrogenic soil profile ( 1 - the difference between tillable and arable horizons; 2 - the difference between arable and subcultivable horizons)

\begin{tabular}{|c|c|c|c|c|c|c|c|c|c|c|c|}
\hline \multirow{2}{*}{\multicolumn{2}{|c|}{ Indicator }} & \multirow{2}{*}{\multicolumn{2}{|c|}{$\begin{array}{c}\text { Calcic } \\
\text { Chernozems }\end{array}$}} & \multicolumn{6}{|c|}{ Calcic Chernozems Sodic and Residual-sodic } & \multirow{2}{*}{\multicolumn{2}{|c|}{$\begin{array}{c}\text { Gypsic Kastanozems } \\
\text { Sodic }\end{array}$}} \\
\hline & & & & \multicolumn{2}{|c|}{ plakors } & \multicolumn{2}{|c|}{$\begin{array}{l}\text { upper parts of } \\
\text { slopes }\end{array}$} & \multicolumn{2}{|c|}{$\begin{array}{l}\text { lower parts of } \\
\text { slopes }\end{array}$} & & \\
\hline \multirow{2}{*}{\multicolumn{2}{|c|}{$\begin{array}{c}\text { The difference between } \\
\text { the horizons }\end{array}$}} & \multicolumn{10}{|c|}{$\frac{\text { relative difference }}{\text { absolute difference }}$} \\
\hline & & 1 & 2 & 1 & 2 & 1 & 2 & 1 & 2 & 1 & 2 \\
\hline \multirow{3}{*}{ 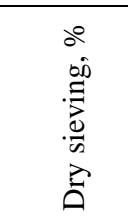 } & $>10$ & $\frac{-50}{-11.0}$ & $\frac{-9}{-2.7}$ & $\frac{-32}{-7.1}$ & $\frac{-16}{-4.8}$ & $\frac{-34}{-7.8}$ & $\frac{-5}{-1.5}$ & $\frac{-33}{-7.9}$ & $\frac{13}{4.0}$ & $\frac{-245}{-26.7}$ & $\frac{31}{11.5}$ \\
\hline & $10-0.25$ & $\frac{7}{5.1}$ & $\underline{2}$ & $\frac{2}{1.1}$ & $\frac{3}{1.7}$ & $\frac{3}{1.7}$ & $\frac{1}{0.3}$ & $\frac{9}{6.0}$ & $\frac{-11}{-6.9}$ & $\frac{31}{25.8}$ & $\frac{-17}{-9.8}$ \\
\hline & $<0.25$ & $\frac{60}{5.9}$ & $\frac{40}{1.6}$ & $\frac{47}{5.9}$ & $\frac{48}{3.2}$ & $\frac{44}{6.1}$ & $\frac{17}{1.3}$ & $\frac{19}{1.9}$ & $\frac{35}{2.9}$ & $\frac{18}{0.9}$ & $\frac{-41}{-1.7}$ \\
\hline \multicolumn{2}{|c|}{$\mathrm{SC}$} & $\frac{20}{0.5}$ & $\underline{5}$ & $\underline{5}$ & $\frac{7}{0.1}$ & $\frac{7}{0.1}$ & 0.02 & $\frac{23}{0.4}$ & $\frac{-35}{0.5}$ & $\frac{74}{3.9}$ & $\frac{-52}{-0.7}$ \\
\hline \multicolumn{2}{|c|}{ WRC } & $\frac{-97}{-195.1}$ & - & $\frac{-11}{-20.3}$ & - & $\frac{-71}{-124.0}$ & - & $\frac{-50}{-87.2}$ & - & $\frac{-20}{-29.2}$ & - \\
\hline \multicolumn{2}{|c|}{ IWR } & $\frac{-9}{-6.7}$ & - & $\frac{-11}{-5.9}$ & - & $\frac{-23}{-10.7}$ & - & $\frac{-25}{-13.0}$ & - & $\frac{-56}{-19.4}$ & - \\
\hline \multirow{2}{*}{ 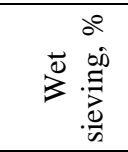 } & $10-0.25$ & $\frac{-1}{-0.5}$ & - & $\frac{-9}{-3.2}$ & - & $\frac{-20}{-5.8}$ & - & $\frac{-14}{-4.7}$ & - & $\frac{-8}{-2.3}$ & - \\
\hline & $<0.25$ & $\frac{1}{0.5}$ & - & $\frac{5}{3.1}$ & - & $\frac{8}{5.8}$ & - & $\frac{7}{4.7}$ & - & $\frac{3}{2.3}$ & - \\
\hline
\end{tabular}

The spatial difference in the characteristics of aggregates water stability (the value of WRC and IWR decreases from the west to the east: from the calcic chernozems to the gypsic kastanozems) is due to the higher resistance of the aggregates of the chernozems to the destructive action of water. The faster rates of degradation of the aggregate composition characteristics of the arable horizons of gypsic kastanozems and the soils of the upper parts of the slopes are noticeable if compared to calcic chernozems. The content of structural aggregates of 1-0.25 mm in case of dry sieving in gypsic kastanozems is higher by $20 \%$, but the content of aggregates of the same size at wet sieving in them naturally decreases by $22 \%$, which, in turn, leads to a decrease in the IWR by $40 \%$ in comparison to calcic chernozems (Table 2 ). This is a sign of the formation of unstable aggregates (which are cemented with sodium cations) or a result of the mechanical crushing of the crust formed during the flooding of the surface after rainfalls.

Informative is the tendency to decrease the difference between the tillable and the arable horizons from calcic chernozems to gypsic kastanozems based on the WRC (97-20\%) and its increase according to IWR (9-56\%) (Table 3). This is an evidence of a better water resistance of aggregates in the size of 1-10 mm in gypsic kastanozems, and of aggregates of 1-0.25 $\mathrm{mm}$ in the calcic chernozems.

Thus, the results summarizing the materials of the study of agropedogenic evolution of the physical properties of soils in the medium-dry steppe pedo-ecotone of the Northwest of the Black Sea region indicate the negative, in general, impact of agricultural use on their most important indicators: the deterioration of the aggregate composition, decreasing of water resistance, appearance of clodding and flooding after rainfalls, deterioration of permeability and aeration due to the formation of the subplough sole and after the consolidation of the soil by chassis of the tractors, that, in general, makes reducing the biological activity.

\section{CONCLUSIONS}

1. As a result of a prolonged agrogenic impact, the humus part of the natural soil profile within the territory of research was clearly divided into two horizons - cultivable $(12-30 \mathrm{~cm})$ and subcultivable $(30-55 \mathrm{~cm})$. The upper horizon is often divided into two layers - tillable $(0-12 \mathrm{~cm})$ and arable $(12-30 \mathrm{~cm})$. 
2. In the medium-dry steppe pedo-ecotone of the Northwest of the Black Sea region, there is a significant degradation of the physical properties of the arable horizons (in comparison to the tillable and the subcultivable horizons), as well as the deterioration of the water resistance of the aggregates of the tillable horizons (as compared to the arable), which is obviously directly related to the agrogenic influence on the soil.

3. In the spatial aspect, the degree of anthropogenic transformation of physical properties of soils increases from calcic chernozems to gypsic kastanozems.

\section{REFERENCES}

1. Dazzi, C., Lo Papa, G. 2015. Anthropogenic soils: general aspects and features. Ecocycles, Vol. 1, No. 1, pp. 3-8. http://dx.doi.org/10.19040/ecocycles.v1i1.23

2. Degradation and protection of soils. 2002. Moscow: Publishing House of Moscow State University, 654 p. [In Russian].

3. Jovanov, D., Mitkova, T., Ilievski, M. 2012. Aggregate composition and water stability of structural aggregates of vertisols spread out in Stip, Probištip and Ovče Pole valleys. Jornal of Central European Agriculture, Vol. 13, No. 3, pp. $483-492$. http://dx.doi.org/10.5513/jcea.v13i3.1538

4. Howard, J. Anthropogenic soils. 2017. Springer International Publishing, 231 p. https://doi.org/10.1007/978-3-319-54331-4

5. Jigau, Gh. 2008. Estimation of the factors and systematization of modern processes of chernozems evolution of the Prut-Danube region. Agrochemistry and soil science, Iss. 69, pp. 112-121 [In Russian].

6. Jigau, Gh., Blidari, A., Bors, N., Birsan, A. 2017. Elements of evolution of the relations between the soils and the climate in the territory between Prut and Nistru in the context of climatic changes and natural - antropic pedogenesis. Present Environment and Sustainable Development, Vol. 11, Iss. 2, pp. 233-246. https://doi.org/10.1515/pesd-2017-0039.

7. Karavaeva, N. 2005. Agrogenic Soils: Environmental Conditions,Properties and Processes. Eurasian Soil Science. No. 12, pp. 1518-1529 [In Russian].

8. Laktionov, N. 1970. Agricultural use of soils and colloidal humus. Proceedings of the KACI, Vol. 193, pp. 9-15 [In Russian].

9. Nosko, B. 2006. Anthropogenic evolution of chernozems. Kharkiv: "13th typography", 240 p. [In Ukrainian].

10. Nosko, B. 2013. The formation of the agrogenic typical chernozem profile in the Ukrainian forest-steppe after plowing virgin steppe and fallow soils. Eurasian Soil Science, No. 3, pp. 359-371. https://doi.org/10.1134/S1064229313030058

11. Paluszek, J. 2014. Air-dry and water-stable soil aggregate distribution of Polish Chernozems classified in various complexes of agricultural suitability. Polish Journal of Environmental Studies, Vol. 23, No. 3. pp. 813-821.

12. Theory and Methods of Soils Physics. 2007. Edited by Shein E., Karpachevskii L. "Grif and K”, Moscow, 614 p. [In Russian].

13. Volungevičius, J., Skorupskas, R. 2011. Classifcation of anthropogenic soil transformation. Geologija, Vol. 53, No. 4(76), pp. 165-177. https://doi.org/10.6001/geologija.v53i4.1904

14. Zalibekov, Z, Biarslanov, A. 2015. Development of anthropogenic soil science as a separate branch of science. Arid ecosystems, Vol. 21, No. 1(62), pp. 5-16. https://doi.org/10.1134/S2079096115010114 